\title{
Christopher Brumfit Ph.D./Ed.D. Thesis Award 2007
}

\section{Sponsored by Cambridge University Press and promoted by Language Teaching}

The Editor and Board of Language Teaching are pleased to announce that the recipient of the 2007 Christopher Brumfit thesis award is Dr IRINA ELGORT.

Dr Elgort's Ph.D. thesis, entitled 'The role of intentional decontextualised learning in second language vocabulary acquisition', was selected by an external panel of judges based on its significance to the field of second or foreign language learning and teaching, originality and creativity, and quality of presentation. The study investigates the effect of intentional decontextualised learning on L2 vocabulary acquisition. Three experiments were designed to measure acquisition of a set of studied pseudowords across the representational and processing knowledge domains using a lexical decision task with visually presented stimuli and three priming procedures. In each experiment, the findings were examined to test whether the expected perceptual effects had occurred, and whether the patterns of results observed with the newly-learned vocabulary items aligned with low-frequency English words or with non-words in the same experiments. Overall, the findings that both formal-lexical and lexical-semantic representations of the newly-learned vocabulary items had been established and integrated into the mental lexicon of the bilingual subjects demonstrated that intentional decontextualised learning triggered acquisition of representational knowledge of these items.

The judges remarked on the thesis's 'well conceptualized and executed' presentation and highlighted the fact that it 'supports a particular pedagogical approach to vocabulary acquisition by advanced learners, makes an original contribution to the acquisition/learning debate in SLA, and implements an eminently replicable series of experiments. It thus carries an unusually rich set of implications for further research'. Dr Elgort completed her dissertation at the Victoria University of Wellington in New Zealand under the supervision of Dr Paul Warren and Dr Paul Nation.

This year's runner up was Dr Ute KNOCH. Her Ph.D. thesis, 'Diagnostic writing assessment: The development and validation of a rating scale', on developing a theoreticallybased and empirically-developed rating scale and evaluating whether such a scale functions more reliably and validly in a diagnostic writing context than a pre-existing scale was presented at the University of Auckland, New Zealand, under the supervision of Dr Rod Ellis. It was singled out for praise for its 'exceedingly thorough analysis of data' and 'readerfriendly presentation' together with its 'imagination and creativity in identifying and analysing emergent properties of the data which may not have been foreseen'.

Details of the procedures for the 2008 award are available at http://journals.cambridge. org/action/displaySpecialPage?page Id=664. 